\title{
Effect of lipid and cellulose based matrix former on the release of highly soluble drug from extruded/spheronized, sintered and compacted pellets
}

Madiha Maboos ${ }^{1,2}$, Rabia Ismail Yousuf ${ }^{1}$, Muhammad Harris Shoaib ${ }^{1 *}$ (D), Iqbal Nasiri ${ }^{1}$, Tazeen Hussain ${ }^{1}$, Hafiza Fouzia Ahmed ${ }^{1,2}$ and Wajiha Iffat $^{1}$

\begin{abstract}
Background: The study was to develop an extended release (ER) encapsulated and compacted pellets of Atenolol using hydrophobic (wax based and polymeric based) and high viscosity grade hydrophilic matrix formers to control the release of this highly water soluble drug by extrusion/spheronization (ES). Atenolol is used for cardiovascular diseases and available as an immediate release (IR) tablet dosage form. The lipids, Carnauba wax (CW), Glyceryl monostearate (GMS) and cellulose based i.e. Hydroxypropyl methylcellulose (HPMC) and Ethyl cellulose (EC) were used in preparing Atenolol ER pellets. Thermal sintering and compaction techniques were also applied to control the burst release of Atenolol.

Method: For this purpose, thirty-six trial formulations (F1-F36) were designed by Response Surface Methodology (RSM), using Design-Expert 10 software, keeping (HPMC K4M, K15 M \& K100 M), (EC 7FP, 10FP \& 100FP), waxes (GMS, \& CW), their combinations, sintering temperature and duration, as input variables. Dissolution studies were performed in pH, 1.2, 4.5 and 6.8 dissolution media. Drug release kinetics using different models such as zero order, first order, Korsmeyer-Peppas, Hixon Crowell, Baker-Lonsdale and Higuchi kinetics were studied with the help of DDsolver, an excel based add-in program.
\end{abstract}

Results: The formulations F35 and F36 showed compliance with Korsmeyer-Peppas Super case II transport model $\left(\mathrm{R}^{2}=0.975-0.971\right)$ in dissolution medium pH 4.5. No drug excipient interaction observed by FTIR. Stereomicroscopy showed that sintered combination pellets, (F35), were highly spherical ( $A R=1.061$, and sphericity $=0.943)$. The cross-sectional SEM magnification (at 7000X) of F34 and F35 showed dense cross-linking. The results revealed that the optimized formulations were F35 (sintered pellets) and F36 (compacted pellets) effectively controlling the drug release for $12 \mathrm{~h}$.

Conclusion: Extended-release encapsulated, and compacted pellets were successfully prepared after the combination of lipids CW (10\%) and GMS (20\%) with EC (10FP 20\% \& 100FP 20\%). Sintering and compaction, in addition, stabilized the system and controlled the initial burst release of the drug. Extended release (ER) Atenolol is an effective alternative of IR tablets in controlling hypertension and treating other cardiovascular diseases.

Keywords: Atenolol, Pellets, Extended release, Extrusion-Spheronization, Carnauba wax (CW), Glyceryl monostearate (GMS), Hydroxypropyl methylcellulose (HPMC), Ethyl cellulose (EC), Fourier transform spectroscopy (FTIR), Scanning Electron microscopy (SEM)

\footnotetext{
* Correspondence: harrisshoaib2000@yahoo.com

${ }^{1}$ Department of Pharmaceutics, Faculty of Pharmacy and Pharmaceutical

Sciences, University of Karachi, Karachi 75270, Pakistan

Full list of author information is available at the end of the article
}

(c) The Author(s). 2018 Open Access This article is distributed under the terms of the Creative Commons Attribution 4.0 International License (http://creativecommons.org/licenses/by/4.0/), which permits unrestricted use, distribution, and reproduction in any medium, provided you give appropriate credit to the original author(s) and the source, provide a link to the Creative Commons license, and indicate if changes were made. The Creative Commons Public Domain Dedication waiver (http://creativecommons.org/publicdomain/zero/1.0/) applies to the data made available in this article, unless otherwise stated. 


\section{Background}

Highly soluble drugs are a big challenge for formulation scientists to be designed as an extended release formulations, because of dose dumping, burst release and non-linear release profile [1]. A suitably designed extended release (ER) delivery system can overcome these issues [2]. Through cross-linking, physical interaction of the hydrophilic drug with lipid and cellulose based matrices can be created to form a monolithic system following zero order drug release [3-5].

Glyceryl monostearate (GMS), the monoglyceride of stearic acid, has been reported as an extrusion aid and rate controlling agent, to retard the release of different drugs from various ER dosage forms. Stearates forms an evenly distributed lipid aggregate layer on the surface of matrix former like HPMC, and this interaction with a polymer forms laminated microstructure moisture barrier [6]. Similarly, carnauba wax is another lipid-based ingredient having a high melting point, that also forms a durable super hydrophobic non-polar lipid layer around pellets [7-9]. It is composed of fatty esters (80-85\%), free alcohols (10-15\%), acids (3-6\%), and hydrocarbons (1-3\%) [10]. Ethyl cellulose is a thermos-insensitive, hydrophobic inert matrix former [11]. It has been used extensively as a sustained release carrier in pharmaceutical and biomedical industries, due to its good biocompatibility and biodegradability, and in combination with other polymers [12].

Sintering is a densification technique and has been applied to different materials for controlling drug release $[13,14]$. Sintering reduces erosion during dissolution, associated with the disintegrating property of microcrystalline cellulose. Materials respond differently at variable temperatures, and percent drug decreases with the rise in sintering temperature [15]. Crack initiation and propagation may occur due to microcrystalline cellulose fibers, which can cause an uncontrolled drug release from weaker and porous pellets. Compaction consolidates the pellets and provides better control on drug release [16].

Atenolol is a cardio-selective beta blocker, widely prescribed as a twice-daily dose for the treatment of hypertension [17] and tachycardia. It is considered as a drug of choice for the prophylaxis of ischemic heart diseases $[18,19]$. Atenolol belongs to BCS (Biopharmaceutical Classification System) class III [20] and has poor absorption rate with $50 \%$ bioavailability and half-life of $6-8 \mathrm{~h}$ only $[21,22]$.

To date, only Atenolol in hydrophobic and hydrophilic matrix combination, has been evaluated, for extended period release [20, 23-26]. Our preliminary objective was to use Atenolol, as a model highly soluble drug, in waxes (CW and GMS), combined with hydroxypropyl methylcellulose and ethyl cellulose could result in an extended release profile of $12 \mathrm{~h}$. The impact of sintering temperature and duration was also studied on 12-h release profile. However, up to now, no report has been found on this matrix and waxes combination due to the effect of sintering and compaction. Response surface methodology (RSM), Central Composite Design (CCD), was applied to explore the effect of different polymers such as HPMC (K4, 15 and $100 \mathrm{M}$ ), EC (7, 10 and 100FP), and waxes (CW and GMS), on the drug release from pellets and their morphology (sphericity and aspect ratio; AR). Thirty-six trial formulations (F1-F36) were designed with the help of Design-Expert version 10 software, keeping polymers, waxes, sintering temperature and duration as input variables, sequential statistical modeling was done to create design space.

\section{Methods}

\section{Materials}

Atenolol was gifted by Searle Pakistan Limited (SPL). Avicel PH101 (FMC Corporation, USA), Glyceryl monostearate (Gattefosse Foundation, Saint-Priest, France), Carnauba wax (BDH Laboratories, England), HPMC (K4, 15 and $100 \mathrm{M})$, EC (7,10 and $100 \mathrm{FP})$ (Colorcon, Kent, England), Potassium dihydrogen phosphate, Sodium hydroxide, Methanol (HPLC grade), Ortho-phosphoric acid (Merck, Darmstadt, Germany), used were of manufacturing and analytical grade and purchased from commercial sources.

\section{Methods}

\section{Calculation of extended release dose}

A single extended release dose of Atenolol was estimated using $25 \mathrm{mg}$ immediate release dose, The calculated sustained dose of Atenolol for $12 \mathrm{~h}$ was found to be $55 \mathrm{mg}$ as per Robinson Eriksson equation and the reported pharmacokinetic data [27, 28]. Pharmacokinetic studies show that $25 \mathrm{mg}$ of Atenolol produce expected therapeutic effects within $2 \mathrm{~h}$ with a half-life of $6 \mathrm{~h}$. Thus, the first order overall elimination rate constant was calculated to be,

$$
k e=0.693 / 6=0.1155 \mathrm{mg} / \mathrm{h}
$$

The availability rate was,

$$
R=K e D=0.1155 \times 25=2.8875 \mathrm{mg} / \mathrm{h}
$$

Where $D$ is the initial dose of the drug. The maintenance dose $D_{\mathrm{m}}$ was calculated as

$$
D_{m}=R h=2.8875 \times 12=34.65 \mathrm{mg}
$$

Where $h$ is the number of hours for which sustained action is desired. 


$$
\begin{aligned}
\text { Total Dose } & =D+D m=25+34.65 \\
& =59.56 \\
& \\
D_{\text {corrected }} & =D-R t_{p}=59.65-2.8875 \times 2 \\
& =53.875 m g(\approx 55 m g)
\end{aligned}
$$

Where, $t_{P}$ is the time required to achieve a peak plasma level. Hence, an oral controlled release formulation of Atenolol should contain a total dose of $53.875 \mathrm{mg}(\approx 55 \mathrm{mg})$.

(Thus, )

(Caleva, Process solution Ltd., Model M.B.S 120, Dorset, UK) at 800-1000 rpm for $15 \mathrm{~min}$. The speed (rpm) and time of spheronization were adjusted for obtaining the spherical granules. The pellets were dried overnight $(8 \mathrm{~h})$ at $35^{\circ} \mathrm{C}$ and then screened through 18 mesh sieve. The recovery of dried pellets was calculated by the following equation [30].

$$
\text { Yield } \%=\frac{\text { Actual weight ofpellets }}{\text { Theoratical weight of pellets }} X 100
$$

\section{Selection of granulating fluid}

To prepare spherical pellets, water alone and water-ethanol mixture $(1: 1)$, were tested as granulating fluids separately, however, pellets with good sphericity and maximum yield were obtained with water [29].

\section{Response surface methodology (RSM)}

The most commonly used RSM technique, Central Composite Design (CCD) was applied by Design-Expert 10 (State-Ease, Inc., USA.). The independent variables were hydroxypropyl methylcellulose (HPMC K4M, K15 M \& K100 M), ethyl cellulose (EC 7FP, 10FP \&100FP), waxes (GMS, \& CW), sintering temperatures $\left(70^{\circ} \mathrm{C}, 80^{\circ} \mathrm{C}\right.$ and $90^{\circ} \mathrm{C}$ ) and duration (60, 90 and $\left.120 \mathrm{~s}\right)$. Their effects were observed on the percentage drug release (1st hour) and morphology (Aspect Ratio; AR) of pellets, as critical parameters. Factor-response relationship was elaborated by the help of a mathematical model and the significance of model was estimated by analysis of variance (ANOVA). The closer the value of the coefficient of determination $\left(r^{2}\right)$ to unity, better would be the model fitting. The model was selected on the basis of minimum values (closer to zero) of standard deviation (SD) and predicted residual error sum of squares (PRESS) that further cross validated the appropriateness of suggested model. The perturbing effect of input variable on critical parameters was shown by perturbation plot and $3 \mathrm{D}$ response surface plot was used to exhibit the relationship between the variables.

\section{Preparation of pellets}

According to the composition of trial batches (Table 1), formulation ingredients were weighed accurately and mixed together for $15 \mathrm{~min}$ in a poly bag. Wet mass of suitable consistency was obtained in a low shear planetary mixer (Kenwood Chef, Hampshire, UK) by adding water as a granulating fluid. The mass was then subjected to $1 \mathrm{~mm}$ screen of the extruder (mini screw laboratory scale, Caleva, Process solution Ltd., Model. M.S.E, Dorset, UK). The extrudates were then immediately transferred to a multi-bowl bench top spheronizer

\section{Sintering and compaction of pellets}

Based on the drug release profile selected batches were subjected to sintering and compaction. Thermal treatment was done at $70^{\circ} \mathrm{C}, 80^{\circ} \mathrm{C}$ and $90^{\circ} \mathrm{C}$ for the duration of 60,90 and $120 \mathrm{~s}$ in a hot air oven. Best sintered pellets were obtained at $90^{\circ} \mathrm{C}$ for $120 \mathrm{~s}$ [15, 31-33].

Formulation F28 (GMS 20\%, CW 10\% and EC 10FP $20 \%$ was selected for compaction. The accurately weighed quantity of pellets containing Atenolol (55 mg) was compressed with Microcrystalline cellulose (as a diluent) by direct compression method on a single punch tablet machine (Korsch, Erweka, Frankfurt Germany), using flat shape punches [34]. The compression forces were kept variable, ranging from $3-7 \mathrm{Kg}$. Finally, the compression force selected was $5 \mathrm{Kg}$, to compact the pellets in the form of a tablet (F36), with suitable strength (hardness) and an average weight of (130 mg).

\section{Fourier transform infrared spectroscopy (FTIR):}

Compatibility and interaction of the pure drug with waxes and polymers was determined by FTIR (Thermo Nicolet Avatar, 330). Infrared spectra of pure drug and formulations were recorded over wave numbers ranging from 4500 to $1000 \mathrm{~cm}^{-1}$ [35].

\section{Flow characterization and compressibility index:}

Samples of $20 \mathrm{~g}$ of pellets were put into $200 \mathrm{~mL}$ graduated cylinder. Bulk density, tap density, Carr's index and Hausner's ratio, were calculated [36, 37].

Angle of repose The angle of repose of all formulations of Atenolol and Glyburide was determined by the fixed base method, using following formula;

$$
\tan \theta=\text { height } / 0.5 \text { base }
$$

Bulk density Bulk Densities of pellets were determined, by pouring $10 \mathrm{~g}$ of pellets in a graduated cylinder, then 
Table 1 The Composition of Atenolol ER matrix pellets formulation

\begin{tabular}{|c|c|c|c|c|c|c|c|c|c|c|c|c|}
\hline \multirow[t]{2}{*}{ FORMULATIONS } & \multirow[b]{2}{*}{ Drug } & \multicolumn{10}{|l|}{$\mathrm{mg}(\%)$} & \multirow[b]{2}{*}{ Total } \\
\hline & & HPMC K4M & HPMC K15M & HPMC K100M & GMS & CW & EC 7FP & EC 10FP & EC 100FP & MCC & $\overline{\text { SINTERING }}$ & \\
\hline F00 & $55(45.8)$ & & & & & & & & & $65(54.1)$ & & $120(100)$ \\
\hline F0 & $55(45.8)$ & & & & & & & & & $65(54.1)$ & & $120(100)$ \\
\hline $\mathrm{F} 1$ & $55(45.8)$ & $6(5)$ & & & & & & & & $59(49.2)$ & & $120(100)$ \\
\hline F2 & 55(45.8) & $24(20)$ & & & & & & & & $41 / 34.2$ & & $120(100)$ \\
\hline F3 & 55(45.8) & & $24(20)$ & & & & & & & $41(34.2)$ & & $120(100)$ \\
\hline F4 & 55(45.8) & & & $24(20)$ & & & & & & $41(34.2)$ & & $120(100)$ \\
\hline F5 & 55(45.8) & & & & $12(10)$ & & & & & $54(45)$ & & $120(100)$ \\
\hline F6 & 55(45.8) & & & & $24(20)$ & & & & & $41(34.2)$ & & $120(100)$ \\
\hline F7 & 55(45.8) & & & & $36(30)$ & & & & & $29(24.2)$ & & $120(100)$ \\
\hline F8 & 55(45.8) & & & & $48(40)$ & & & & & $17(14.2)$ & & $120(100)$ \\
\hline F9 & 55(45.8) & & & & $60(50)$ & & & & & $5(4.2)$ & & $120(100)$ \\
\hline F10 & 55(45.8) & & & & & $6(5)$ & & & & $54(45)$ & & $120(100)$ \\
\hline F11 & 55(45.8) & & & & & $12(10)$ & & & & $54(45)$ & & $120(100)$ \\
\hline $\mathrm{F} 12$ & 55(45.8) & & & & & $12(10)$ & & & & $54(45)$ & & $120(100)$ \\
\hline $\mathrm{F} 13$ & $55(45.8)$ & & & & & 18(15) & & & & $47(39.2)$ & & $120(100)$ \\
\hline F14 & $55(45.8)$ & & & & & $24(20)$ & & & & $41(34.2)$ & & $120(100)$ \\
\hline F15 & $55(45.8)$ & & & & & $24(20)$ & & & & $41(34.2)$ & & $120(100)$ \\
\hline F16 & $55(45.8)$ & $24 / 20$ & & & $12(10)$ & & & & & $29(24.2)$ & & $120(100)$ \\
\hline $\mathrm{F} 17$ & $55(45.8)$ & & & & $36(30)$ & $12(10)$ & & & & $17(14.2)$ & & $120(100)$ \\
\hline F18 & $55(45.8)$ & & & & $36(30)$ & $12(10)$ & & & & $17(14.2)$ & & $120(100)$ \\
\hline F19 & 55(45.8) & & & & & & $24(20)$ & & & $41(34.2)$ & & $120(100)$ \\
\hline F20 & 55(45.8) & & & & & & & $24(20)$ & & $41(34.2)$ & & $120(100)$ \\
\hline F21 & $55(45.8)$ & & & & & & & & $24(20)$ & $41(34.2)$ & & $120(100)$ \\
\hline F22 & 55(45.8) & & & & $24(20)$ & $12 / 10$ & $12(10)$ & & & $17(14.2)$ & & $120(100)$ \\
\hline F23 & 55(45.8) & & & & $24(20)$ & $12(10)$ & $18(15)$ & & & $11(9.2)$ & & $120(100)$ \\
\hline F24 & 55(45.8) & & & & $24(20)$ & $12(10)$ & $24(20)$ & & & $5(4.2)$ & & $120(100)$ \\
\hline F25 & 55(45.8) & & & & $24(20)$ & $12(10)$ & & $6(5)$ & & 23(19.2) & & $120(100)$ \\
\hline F26 & 55(45.8) & & & & $24(20)$ & $12(10)$ & & $12(10)$ & & $17(14.2)$ & & $120(100)$ \\
\hline F27 & 55(45.8) & & & & $24(20)$ & $12(10)$ & & $18(15)$ & & $11(9.2)$ & & $120(100)$ \\
\hline F28 & 55(45.8) & & & & $24(20)$ & $12(10)$ & & $24(20)$ & & $6(5)$ & & $120(100)$ \\
\hline F29 & 55(45.8) & & & & $24(20)$ & $12(10)$ & & & $6(5)$ & 23(19.2) & & $120(100)$ \\
\hline F30 & $55(45.8)$ & & & & $24(20)$ & $12(10)$ & & & $12(10)$ & $17(14.2)$ & & $120(100)$ \\
\hline F31 & $55(45.8)$ & & & & $24(20)$ & $12(10)$ & & & $12(10)$ & $11(9.2)$ & $\sqrt{ }$ & $120(100)$ \\
\hline F32 & $55(45.8)$ & & & & $24(20)$ & $12(10)$ & & & 18(15) & $6(5)$ & & $120(100)$ \\
\hline F33 & $55(45.8)$ & & & & $24(20)$ & $12(10)$ & & & 18(15) & $6(5)$ & $\sqrt{ }$ & $120(100)$ \\
\hline F34 & $55(45.8)$ & & & & $24(20)$ & $12(10)$ & & & $24 / 20$ & & & $120(100)$ \\
\hline F35 & $55(45.8)$ & & & & $24(20)$ & $12(10)$ & & & $24 / 20$ & & $\sqrt{ }$ & $120(100)$ \\
\hline
\end{tabular}


bulk volumes were measured in $\mathrm{ml}$ and bulk densities were calculated.

$$
\text { Bulk Density }=\frac{\text { Mass }}{\text { Bulk Volume }}
$$

Tapped density Tapped density was determined by tapping the graduated cylinder (till no further reduction in volume was observed). Tapped density was then calculated as follows

$$
\text { Tapped Density }=\frac{\text { Mass }}{\text { Tapped Volume }}
$$

Carr's index Compressibility index can be used to predict the flow property and is based on the density measurements. Carr's index was calculated using the following equation.

$$
\text { Carr's index }(\%)=\frac{(\text { Tapped Density-Poured Density })}{\text { tapped Density }} X 100
$$

Hausner's ratio Flowability of pellets was determined by Hausner using the following equation.

$$
\text { Hausner's Ratio }=\frac{\text { Tapped Density }}{\text { Poured Density }}
$$

\section{Quality evaluation of compacted pellets}

Pharmaceutical quality such as uniformity of weight, hardness, friability, and disintegration of compacted pellets (F36) were evaluated as per pharmacopeial specification [38].

The weight of 20 compacted pellets (Tablets) was observed using analytical weighing balance (Sartorius, Goettingen, Germany), Tablet Hardness (crushing strength) using hardness tester (OSK-Fujiwara Seiki, Japan) and Friability Test was performed on Roche type friabilator (Erweka, Husenstamm, Germany). Disintegration time was observed for 6 tablets using USP Disintegration apparatus (Erweka, Heusenstamm, Germany).

\section{Encapsulation of pellets}

The weight of pellet formulations (F00-F35), holding the accurate amount of the sustained dose of Atenolol (55 mg), was $120 \mathrm{mg}$, that was encapsulated directly into the hard gelatin capsule size of 00 .

\section{Assay of compacted and encapsulated pellets}

Sample preparation An average weight of one capsule was taken after weighing 10 capsules from each formulation. Pellets were triturated using Mortar and pestle making the final strength of $30 \mu \mathrm{g} / \mathrm{ml}$ of Atenolol in Methanol. Glyburide was taken as an Internal standard with a concentration of $15 \mu \mathrm{g} / \mathrm{ml}$ of Glyburide, content was sonicated with Digital Ultrasonic Cleaner (Supersonic X3, Germany) for $15 \mathrm{~min}$, then the volume was made up in $25 \mathrm{ml}$ volumetric flask. The same procedure was carried out to prepare reference standard solutions of Atenolol and Glyburide. The same procedure was adopted for compacted pellets where 10 tablets were crushed with the help of Mortar and pestle.

Mobile phase The mobile phase was prepared by the addition of 20 parts of distilled water in 80 parts of HPLC grade Methanol (Merck KGaA, Darmstadt, Germany) and $\mathrm{pH}$ was adjusted to $3.4 \pm 0.2$ with Ortho-Phosphoric acid (Merck KGaA, Darmstadt, Germany). The mobile phase was filtered using $0.45 \mu$ filter and sonicated with Digital Ultrasonic Cleaner (Supersonic X3, Germany).

Chromatographic condition An isocratic high performance liquid chromatographic method using Shimadzu HPLC system having pump LC-10AT VP and SPD-10AVP as UV detector (Shimadzu Corp. Kyoto, Japan) with C18 column (5um, $250 \times 4.6 \mathrm{~mm}$ ) (Phenomenex, Torrance, USA) was used for separating and estimating drug content. The flow rate was $1 \mathrm{ml} / \mathrm{min}$ and the volume of injection was $20 \mu \mathrm{l}$. The wavelength of detection was $235 \mathrm{~nm}$.

Limits: $90-110 \%$.

\section{In vitro drug release study}

The dissolution profiles of formulations (F00-F35) were generated by performing multiple point dissolution studies in $900 \mathrm{ml}$ of $\mathrm{pH} \mathrm{1.2,} 4.5$ and 6.8 buffers as a dissolution media using USP dissolution apparatus I (Erweka, Heusenstamm, Germany) at $50 \mathrm{rpm}$. Ten $\mathrm{ml}$ of sample were drawn at $0.5,1,2,3,4,5,6,7$, $8,9,10,11$ and $12 \mathrm{~h}$ and sink condition was maintained. The percentage drug release was determined on UV-VIS Spectrophotometer (UV- 1800 Shimadzu Corp, Japan) at $\lambda_{\max }=275 \mathrm{~nm}$. USP dissolution apparatus II was used to study the dissolution profile of formulation F36 (compressed pellets) only, under the same dissolution conditions [39, 40].

\section{Release kinetics and mechanism:}

Drug release kinetics and mechanism of successful formulations were assessed using DDSolver, an Excel based 
Add-in program for the following models [41]. In these models, ' $F$ ' is the amount of drug released at time ' $t$ ', and ' $\mathrm{k}$ ' is a dissolution rate constant.

- Model I: First order kinetics

$$
F=100\left(1-e^{-k t}\right)
$$

Drug release is proportional to the amount of drug remaining in dosage form so that the amount of drug release diminishes per unit of time.
- Model II: Zero-order kinetics

Drug dissolution from rate-controlled dosage forms are best explained by zero order kinetics. It can be expressed as,

$$
Q_{t}=Q_{o}+K_{o} t
$$

Where $\mathrm{Q}_{t}$ is the amount of drug dissolved in time $t, Q_{0}$ is the initial amount of drug in the solution and $K_{0}$ is the zero order release constant expressed in units of concentration/time [42].

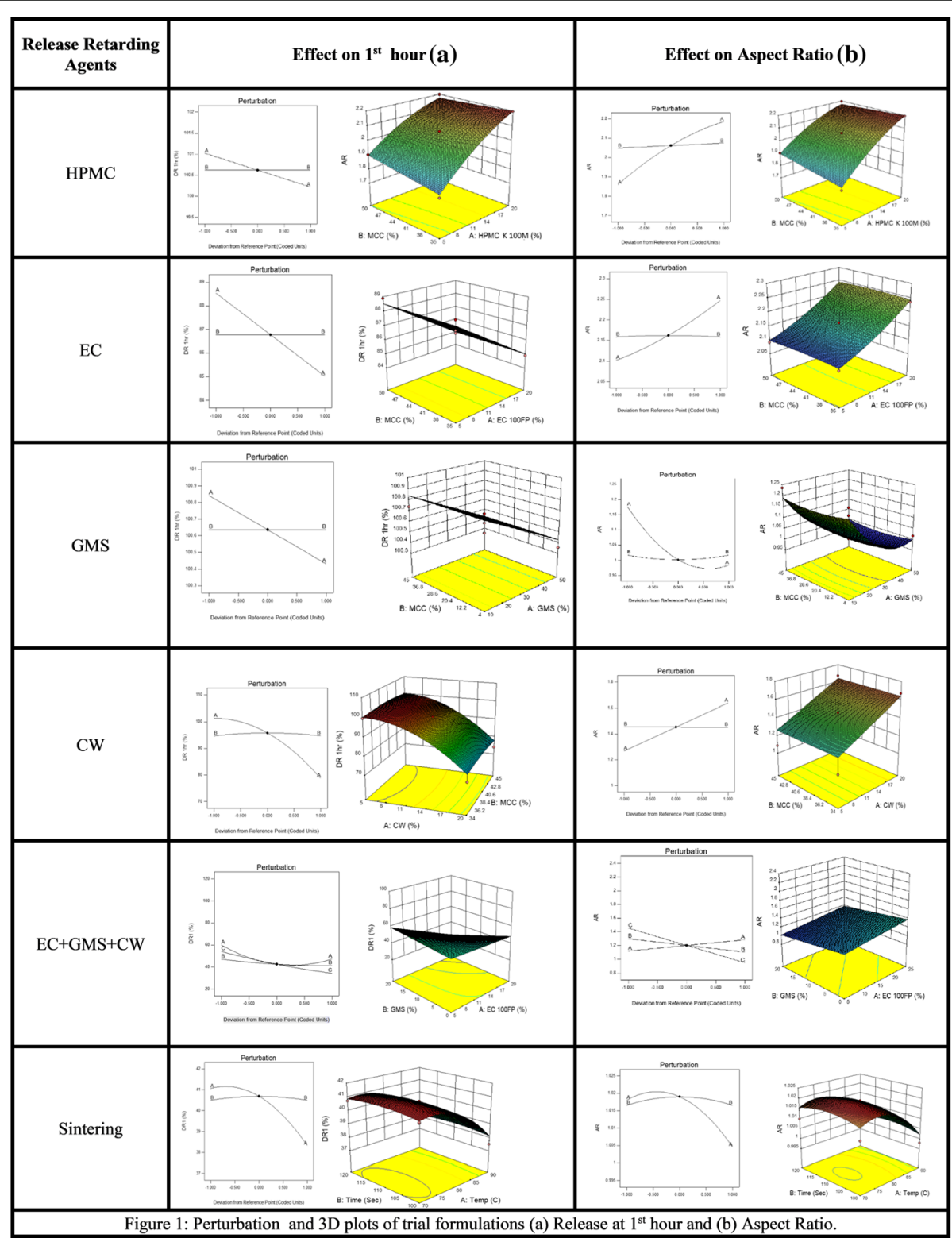

Fig. 1 Perturbation and 3D plots of trial formulations (a) Release at 1st hour and (b) Aspect Ratio 
Table 2 Image analysis of matrix and sintered formulations

\begin{tabular}{|c|c|c|c|c|c|c|}
\hline Formulations & Area & Perimeter & Circumference & Feret Diameter & Aspect Ratio & Sphericity \\
\hline F00 & 37,632 & 688.009 & 0.999 & 226.883 & 1.066 & 0.938 \\
\hline F0 & 30,484 & 618.894 & 1 & 202.988 & 1.052 & 0.951 \\
\hline $\mathrm{F} 1$ & 15,453 & 545.717 & 0.652 & 187.182 & 1.764 & 0.567 \\
\hline F2 & 18,006 & 561.265 & 0.718 & 202.41 & 1.928 & 0.519 \\
\hline F3 & 23,448 & 689.207 & 0.62 & 254.167 & 2.517 & 0.397 \\
\hline $\mathrm{F} 4$ & 13,765 & 502.334 & 0.685 & 177.505 & 1.646 & 0.608 \\
\hline F5 & 13,502 & 413.119 & 0.994 & 142.79 & 1.174 & 0.852 \\
\hline F6 & 8957 & 336.15 & 0.996 & 113.745 & 1.119 & 0.894 \\
\hline F7 & 12,079 & 389.557 & 1 & 127.883 & 1.048 & 0.954 \\
\hline F8 & 9258 & 340.863 & 1 & 111.018 & 1.027 & 0.973 \\
\hline F9 & 11,516 & 380.133 & 1 & 123.045 & 1.017 & 0.984 \\
\hline F10 & 13,208 & 444.987 & 0.838 & 158.028 & 1.528 & 0.655 \\
\hline F11 & 11,243 & 413.361 & 0.827 & 140.46 & 1.268 & 0.789 \\
\hline $\mathrm{F} 12$ & 16,118 & 516.55 & 0.759 & 179.477 & 1.689 & 0.592 \\
\hline F13 & 17,678 & 575.009 & 0.672 & 229.369 & 2.364 & 0.423 \\
\hline F14 & 18,515 & 592.862 & 0.662 & 231.683 & 2.483 & 0.403 \\
\hline F15 & 26,743 & 656.143 & 0.781 & 258.606 & 1.883 & 0.531 \\
\hline F16 & 25,230 & 626.354 & 0.808 & 234.196 & 1.694 & 0.59 \\
\hline F17 & 11,738 & 384.845 & 0.996 & 131.746 & 1.149 & 0.87 \\
\hline F18 & 8371 & 326.726 & 0.985 & 117.516 & 1.286 & 0.778 \\
\hline F19 & 12,975 & 457.073 & 0.78 & 154.311 & 1.412 & 0.708 \\
\hline F20 & 9916 & 412.01 & 0.734 & 123.794 & 1.605 & 0.752 \\
\hline F21 & 6586 & 287.456 & 1 & 94.895 & 1.756 & 0.647 \\
\hline F22 & 6643 & 289.027 & 0.999 & 95.885 & 1.067 & 0.937 \\
\hline F23 & 6988 & 301.593 & 0.965 & 114.438 & 1.458 & 0.686 \\
\hline F24 & 7010 & 296.881 & 0.999 & 98.858 & 1.078 & 0.928 \\
\hline F25 & 7952 & 317.301 & 0.993 & 110.653 & 1.196 & 0.836 \\
\hline F26 & 11,208 & 375.42 & 0.999 & 123.794 & 1.059 & 0.944 \\
\hline $\mathrm{F} 27$ & 8952 & 337.721 & 0.986 & 120.702 & 1.263 & 0.792 \\
\hline F28 & 8906 & 334.58 & 1 & 108.005 & 1.008 & 0.992 \\
\hline F29 & 9001 & 336.15 & 1 & 108.268 & 1 & 1 \\
\hline F30 & 13,271 & 408.407 & 1 & 131.947 & 1.014 & 0.986 \\
\hline F31 & 11,703 & 383.274 & 1 & 124.04 & 1.017 & 0.983 \\
\hline F32 & 9238 & 340.863 & 0.999 & 114.739 & 1.106 & 0.904 \\
\hline F33 & 13,901 & 417.832 & 1 & 135.831 & 1.029 & 0.971 \\
\hline F34 & 11,872 & 386.416 & 0.999 & 127.012 & 1.051 & 0.951 \\
\hline F35 & 8175 & 320.442 & 1 & 105.802 & 1.061 & 0.943 \\
\hline
\end{tabular}


- Model III: Higuchi Kinetics

$$
F=k \sqrt{t}
$$

To determine the process of diffusion through a reasonably intact matrix Higuchi model was applied [43].

- Model IV: Baker and Lonsdale Model

$$
k t=2 / 3\left[1-(1-F)^{2 / 3}\right]-F
$$

The model was applied to know the release control of drug from the matrix, if the matrix was homogeneous and/or not fractured or containing no capillaries, could affect the amount and rate of drug release [44].

- Model V: Hixson and Crowell Model

$$
F=100\left[1-(1-k t)^{3}\right]
$$

This equation is applicable to evaluate the dissolution behavior of uniformly sized particles like pellets and was used to study the effect of surface area on the dissolution of drug from matrix [45].

\section{- Model VI: Korsmeyer and Peppas Model}

The mode was used to study the drug release mechanism and rate of drug release as a function of time.

$$
F=k t^{n}
$$

Where,

\begin{tabular}{lll}
\hline $\begin{array}{l}\text { Release exponent } \\
(n)\end{array}$ & $\begin{array}{l}\text { Drug Release } \\
\text { mechanism }\end{array}$ & $\begin{array}{l}\text { Rate as a function of } \\
\text { time }\end{array}$ \\
\hline 0.5 & Fickian diffusion & $t^{-0.5}$ \\
$0.5<n<1.0$ & Anomalous Transport & $t^{n-1}$ \\
1.0 & Case-II transport & Zero order release \\
Higher then 1.0 & Super Case-II Transport & $i^{\text {n-1 }}$ \\
Interpretation of diffusional release mechanisms from polymer [46-48]
\end{tabular}

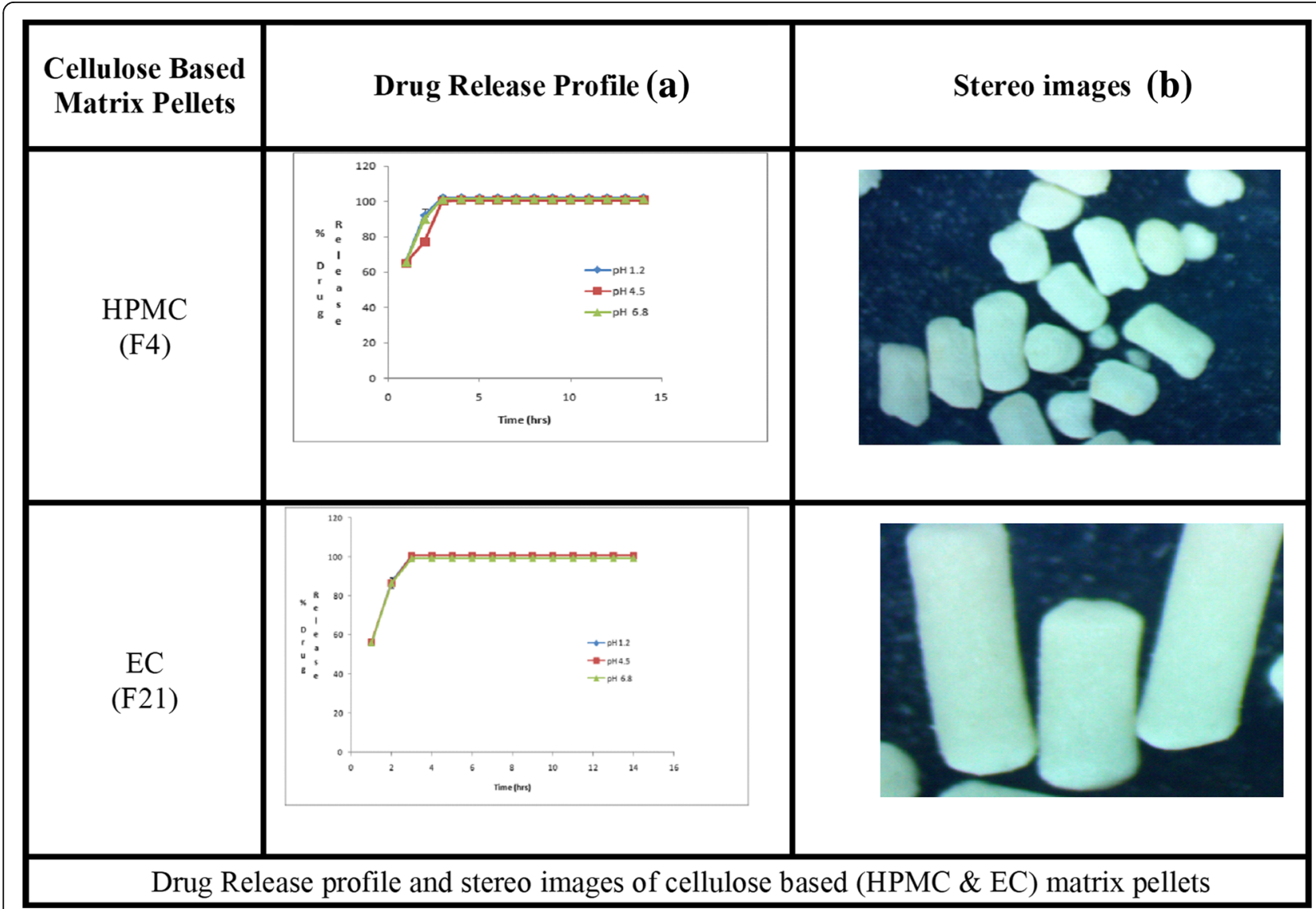

Fig. 2 Drug Release profile and stereomicroscopic images of cellulose based (HPMC \& EC) matrix pellets 


\section{Image analysis of pellets:}

Photomicrographs of pellets $(n \geq 50)$ were taken with a stereomicroscope (Amscope Digital, LED-1444A, USA) at $10 \mathrm{X}$ magnification, to obtain top light illumination of the pellets against a dark surface. Images were analyzed by image analysis software (NIH Image J $1.47 \mathrm{v}$, USA). Samples of each batch was characterized by means of Feret diameter $\left(e_{R}\right)$ (Eq.17) (average of 180 caliper measurements with an angle of rotation of $1^{\circ}$ ), aspect ratio (AR) (Eq.10) (ratio of longest Feret diameter and its longest perpendicular diameter) and two-dimensional shape factor or sphericity (Eq.19) [49].

$$
e_{R}=\frac{2 \pi}{P} \frac{r_{e}}{f}-\sqrt{1-\left(\frac{b}{1}\right)^{2}}
$$

Where $\mathrm{r}$ is the radius, $\mathrm{P}_{\mathrm{m}}$ is the perimeter, $\mathrm{l}$ is the length (longest Feret diameter) and $b$ is the breadth (longest diameter perpendicular to the longest Feret diameter) of a pellet. An average value for all pellets was calculated as the mean pellet size (mean FD).

$$
\begin{aligned}
& \text { Sphericity }=\frac{4 \pi A}{\mathcal{P}_{m}^{2}} \\
& \text { Aspect ratio }=\frac{d \max }{d m i n}
\end{aligned}
$$

Where $d_{\max }$ and $d_{\min }$ were the longest and shortest Feret diameters measured respectively.

\section{Surface morphology:}

Morphology of the pellets was determined by SEM (JSM-6380A, Jeol, Japan). Pellets were coated with a gold film by Auto Coater (JFC-1500, Jeol, Japan) to assure conductivity, and scanning was performed under different magnifications ranging from 93,500 to 911,000 at $16 \mathrm{kV}$ voltage. Photomicrographs were taken with a scanning electron microscope and measured at four sites per pellet.

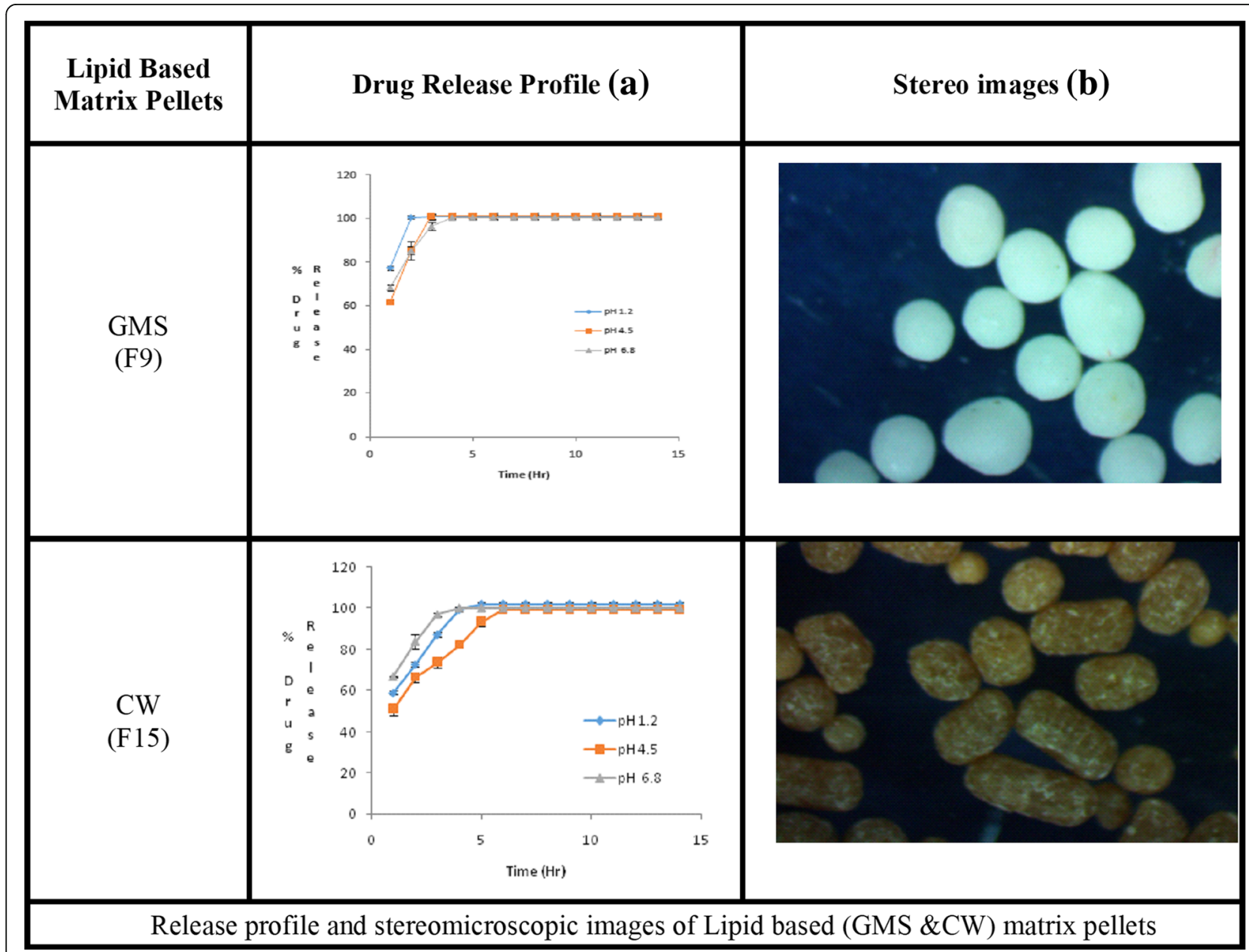

Fig. 3 Release profile and stereomicroscopic images of Lipid based (GMS \&CW) matrix pellets 


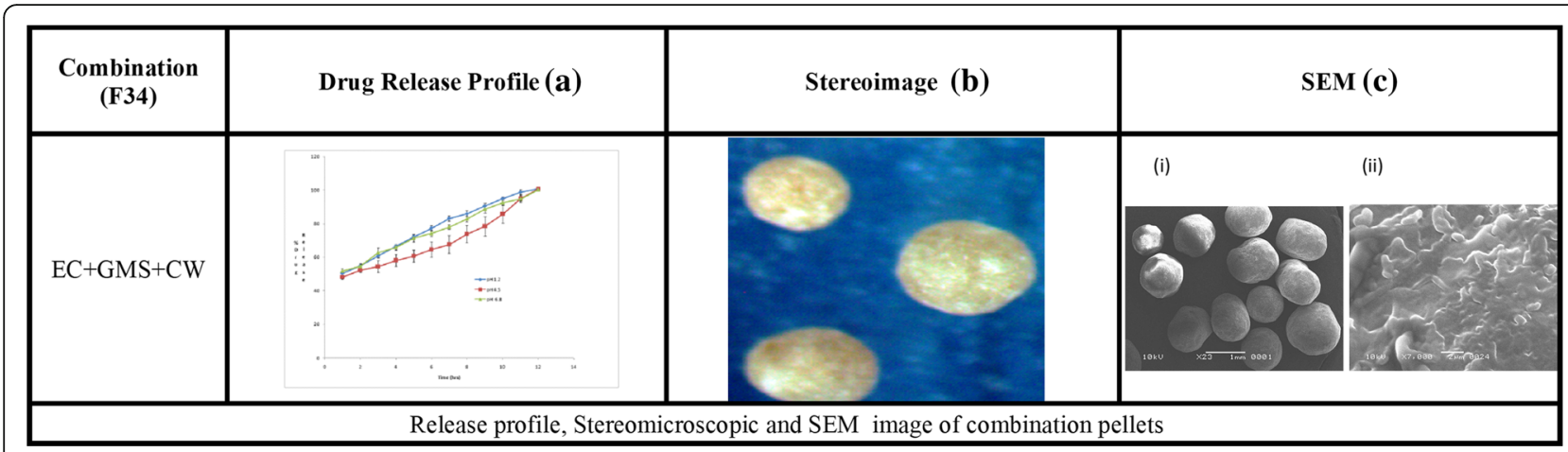

Fig. 4 Release profile, Stereomicroscopic and SEM image of combination pellets

\section{Stability studies:}

Extended release optimized formulation (F35 and F36) were stored for 12 months at $40 \pm 2{ }^{\circ} \mathrm{C} / 75 \% \pm 5 \% \mathrm{RH}$ (relative humidity), as per the guidelines of International Conference on Harmonization (ICH). Sintered encapsulated (F35) and compacted pellets (F36) were placed in amber glass bottles and stored in a humidity chamber (Nuaire, USA). Samples were drawn every 3 months and their physical appearance, drug content and release characteristics in different dissolution medium i.e. $\mathrm{pH} 1.2,4.5$ and 6.8 were determined. The shelf life of optimized formulation was calculated using shelf life calculation feature of Minitab software version 17 [50].

\section{Results}

\section{Selection of granulating fluid}

Initially, two formulations (F00 and F0) were prepared (Table 1) with the different composition of granulating fluid i.e. water alone and a mixture of water and ethanol (1:1) respectively. Sphericity and better yield were obtained by using water alone as a granulating fluid.

\section{Response surface methodology}

Figure 1 (a), shows the perturbing effect of input variables on drug release at 1st hour and aspect ratio (AR). Lipids (CW and GMS) and polymers (HPMC and EC), when used alone and in combination, influenced the atenolol release. The presence of microcrystalline cellulose (MCC), however, did not affect the rate of drug release. The rate of dissolution was observed to be affected by the rise in sintering temperature, contrarily, the duration of thermal treatment did not change the drug release evidently. The 3D plots of Fig. 1 (a), shows that when used alone or in combination, the maximum concentrations of high viscosity grades of polymers (HPMC K100 M\& EC100 FP) and waxes (GMS \& CW), could not control the release of atenolol, and maximum drug release was found within 1 st hour.

Figure 1 (b) depicts that Aspect ratio (AR) also changed with the concentrations of polymers and waxes. The pellets prepared by using water as a granulating fluid had better sphericity and AR $(0.951 ; 1.052)$ than pellets prepared by ethanol and water mixture (0.938, 1.066). Pellets containing HPMC and EC had poor morphology i.e. $(\mathrm{AR}=1.764-2.517$, sphericity $=0.396-$ $0.608)$ and $(\mathrm{AR}=1.412-1.756$, sphericity $=0.647-0.752)$

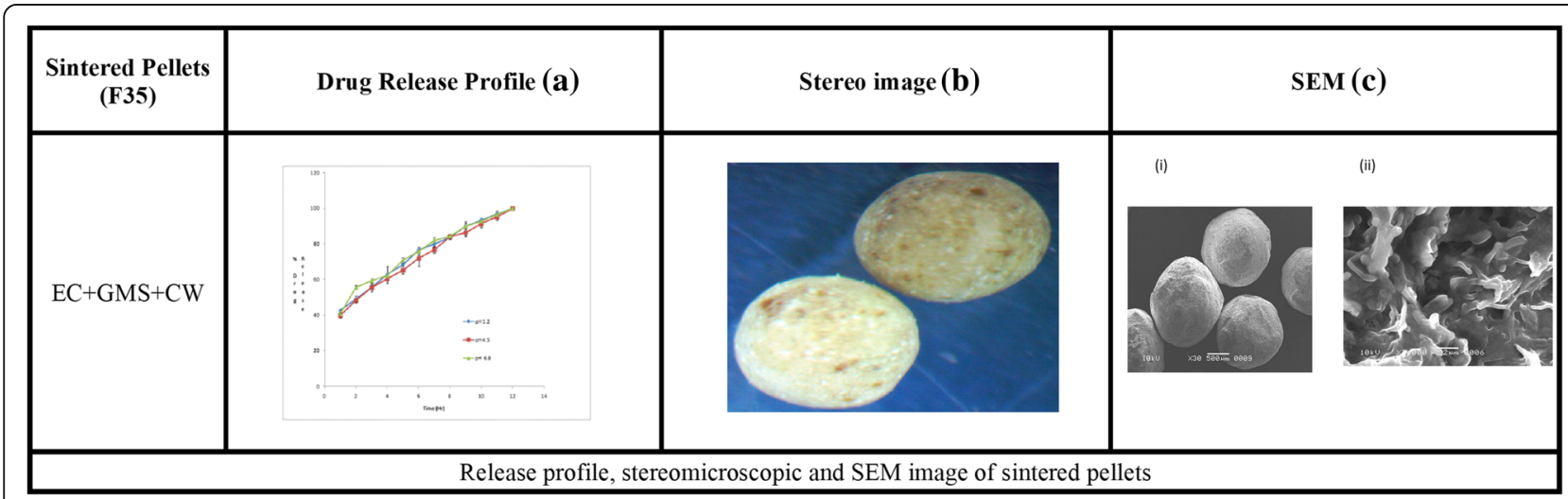

Fig. 5 Release profile, stereomicroscopic and SEM image of sintered pellets 
respectively. The best shape was obtained at the maximum concentration of GMS (AR $=1.017$, sphericity $=0.984$ ), but pellets containing $\mathrm{CW}$ had poor $\mathrm{AR}$ (1.268-2.483) and sphericity (0.403-0.655) (Table 2,). The stereo images showing the morphology of atenolol pellets are presented in Figs. 2b and 3b.The stereo-micrographs (Fig. 4b) of the combination pellet
(F34), exhibited good surface morphology (AR $=1.051$, and sphericity $=0.951$ ). Sintering did not affect the shape of the pellets $(\mathrm{AR}=1.061$, and sphericity $=0.943)$ (Fig. 5b). However, the effect of concentration of MCC on the aspect ratio (AR), remained negligible, but sintering temperature, unlike duration of thermal treatment, showed the perturbing effect on it. Atenolol pellets were

Table 3 Physical and chemical evaluation of matrix and sintered pellet formulations

\begin{tabular}{|c|c|c|c|c|c|c|}
\hline Formulations & $\begin{array}{l}\text { Bulk Density } \\
\mathrm{g} / \mathrm{ml}\end{array}$ & $\begin{array}{l}\text { Tapped Density } \\
\mathrm{g} / \mathrm{ml}\end{array}$ & $\begin{array}{l}\text { Angle of Repose } \\
\theta\end{array}$ & $\begin{array}{l}\text { Carr's Index } \\
\%\end{array}$ & Hausner's Ratio & $\begin{array}{l}\text { Assay } \\
\%\end{array}$ \\
\hline$\overline{F 00}$ & 0.625 & 0.704 & 23.08 & 11.222 & 1.126 & 101.481 \\
\hline F0 & 0.557 & 0.597 & 21.23 & 6.700 & 1.072 & 101.373 \\
\hline F1 & 0.675 & 0.709 & 52.19 & 4.795 & 1.050 & 101.872 \\
\hline F2 & 0.687 & 0.712 & 53.23 & 3.511 & 1.036 & 100.998 \\
\hline F3 & 0.654 & 0.698 & 54.18 & 6.304 & 1.067 & 101.623 \\
\hline F4 & 0.769 & 0.806 & 55.54 & 4.591 & 1.048 & 100.749 \\
\hline F5 & 0.826 & 0.931 & 27.56 & 11.278 & 1.127 & 99.987 \\
\hline F6 & 0.8 & 0.967 & 25.27 & 17.270 & 1.209 & 98.765 \\
\hline F7 & 0.654 & 0.765 & 26.15 & 14.510 & 1.170 & 101.675 \\
\hline F8 & 0.554 & 0.578 & 26.56 & 4.152 & 1.043 & 100.765 \\
\hline F9 & 0.567 & 0.6 & 29.54 & 5.500 & 1.058 & 100.653 \\
\hline F10 & 0.674 & 0.713 & 27.56 & 5.470 & 1.058 & 99.765 \\
\hline F11 & 0.598 & 0.67 & 27.89 & 10.746 & 1.120 & 99.876 \\
\hline F12 & 0.479 & 0.501 & 28.98 & 4.391 & 1.046 & 97.676 \\
\hline F13 & 0.675 & 0.698 & 30.23 & 3.295 & 1.034 & 100.109 \\
\hline F14 & 0.775 & 0.891 & 30.78 & 13.019 & 1.150 & 100.657 \\
\hline F15 & 0.765 & 0.865 & 31.78 & 11.561 & 1.131 & 101.762 \\
\hline F16 & 0.567 & 0.613 & 29.76 & 7.504 & 1.081 & 101.765 \\
\hline F17 & 0.767 & 0.897 & 26.67 & 14.493 & 1.169 & 100.765 \\
\hline F18 & 0.765 & 0.887 & 28.56 & 13.754 & 1.159 & 100.675 \\
\hline F19 & 0.897 & 0.953 & 32.33 & 5.876 & 1.062 & 101.876 \\
\hline F20 & 0.785 & 0.866 & 32.87 & 9.353 & 1.103 & 101.767 \\
\hline F21 & 0.764 & 0.824 & 33.32 & 7.282 & 1.079 & 98.765 \\
\hline F22 & 0.745 & 0.867 & 28.56 & 14.072 & 1.164 & 99.762 \\
\hline F23 & 0.699 & 0.765 & 28.76 & 8.627 & 1.094 & 100.765 \\
\hline F24 & 0.776 & 0.845 & 26.87 & 8.166 & 1.089 & 99.765 \\
\hline F25 & 0.798 & 0.878 & 30.76 & 9.112 & 1.100 & 98.766 \\
\hline F26 & 0.687 & 0.786 & 27.67 & 12.595 & 1.144 & 99.765 \\
\hline$F 27$ & 0.657 & 0.759 & 27.56 & 13.439 & 1.155 & 101.673 \\
\hline F28 & 0.765 & 0.823 & 28.65 & 7.047 & 1.076 & 100.783 \\
\hline F29 & 0.734 & 0.845 & 25.22 & 13.136 & 1.151 & 100.786 \\
\hline F30 & 0.765 & 0.876 & 25.87 & 12.671 & 1.145 & 101.783 \\
\hline F31 & 0.734 & 0.823 & 23.78 & 10.814 & 1.121 & 100.672 \\
\hline F32 & 0.71 & 0.83 & 25.78 & 14.458 & 1.169 & 100.37 \\
\hline F33 & 0.76 & 0.9 & 27.4 & 15.556 & 1.184 & 100 \\
\hline F34 & 0.83 & 0.95 & 28.7 & 12.632 & 1.145 & 99.87 \\
\hline F35 & 0.9 & 1.11 & 27.8 & 18.919 & 1.233 & 100.12 \\
\hline
\end{tabular}


subjected to physical testing like bulk density, tapped density, angle of repose, Carr's index, and Hausner's ratio, and results were obtained within the official range as per USP NF30. Percent assay of pellet formulations (F00-F35) were determined and found in compliance with the official reference range (90-110\%) (Table 3).

\section{Effect of polymers and waxes on drug release}

In all dissolution media ( $\mathrm{pH}$ 1.2, 4.5 and 6.8), formulations containing highest concentrations of HPMC K100 M (F4) and EC 100FP (F21), remained unable to control the atenolol release, for an extended period (12 h) and maximum drug released was obtained within $5 \mathrm{~h}$ (Fig. 2a). Even the lipid-based matrix formers in their highest concentrations (GMS 50\% and CW 20\%) failed to control the atenolol release from pellets (Fig. 3a). The combination pellets (F34), exhibited drug release control up to $12 \mathrm{~h}$ but initial burst release was observed in 1 st hour $(50.3 \%$ at $\mathrm{pH} 1.2,48.14 \%$ at $\mathrm{pH} 4.5$ and $51.79 \%$ at 6.8 ) as shown in Fig. $4 \mathrm{a}$.

\section{Effect of sintering}

The burst release at first hour was controlled after the thermal treatment at the optimized temperature and duration of $90{ }^{\circ} \mathrm{C}$ and $120 \mathrm{~s}$. after thermal treatment, the release was found to be reduced from 50.30 to $42.40 \%$, 48.14 to $39.67 \%$ and 51.79 to $40.67 \%$ at $\mathrm{pH} 1.2,4.5$ and 6.8 respectively (Fig. $5 \mathrm{a})$.

\section{Effect of compaction}

The combination pellets (F28) with the maximum concentrations of EC10FP, CW and GMS were also compacted into tablets (F36) at the optimized compression force of $5 \mathrm{~kg}$, in order to control the burst release at 1 st hour and drug release up to $12 \mathrm{~h}$. After compaction, atenolol release at 1 st hour $(59.50 \%$ at $\mathrm{pH} 1.2,71.17 \%$ at $\mathrm{pH} 4.5$ and $80.07 \%$ at $\mathrm{pH} 6.8$ ), was reduced to $33.5 \%(\mathrm{pH} 1.2), 36.90 \%(\mathrm{pH} 4.5)$ and $47.09 \%$
( $\mathrm{pH}$ 6.8). The compaction also prolonged the atenolol release from pellets, i.e. from 6 to $12 \mathrm{~h}$ (Fig. $6 \mathrm{a}$ and b). The pharmaceutical quality characteristics of compacted pellets (F36) are given in Table 4. The weight variation, hardness, friability disintegration time and content assay were found to be within the pharmacopeial limits.

\section{Scanning Electron microscopy (SEM) of pellets}

The cross-sectional scanning electron micrographs of F34, F35 showed cross-linking at 7000X magnification that was observed to be more dense and complex upon thermal treatment (Fig. $4 \mathrm{c}$ ii and $5 \mathrm{c}$ ii). The surface morphology of these polymers and wax based pellets was also smooth and spherical as shown in Fig. 4ci and 5ci. The smoothness, however, was found little more improved after thermal treatment Fig. 5ci, whereas, the overall appearance of both the formulations was similar as given in stereo images Fig. 4b and 5b. The SEM images and stereographs indicated that the surface morphology of the pellets was independent of the thermal treatment.

The SEM image Fig. 6c of compacted pellets (F36) showed that the integrity of pellets remained intact and become closer after the application of compression force.

\section{Fourier transform infrared spectroscopy (FTIR):}

Compatibility study among drug, polymers, and waxes, was performed using FTIR technique and the spectra exhibited absence of any interaction. The spectra of pure Atenolol at $3368 \mathbf{c m}^{-1}(-\mathrm{OH}), 3198-3071 \mathbf{c m}^{-1}(\mathrm{H}-\mathrm{N}), 2966 \mathbf{c m}^{-1}$ (C-CH3), $2924 \mathbf{~ c m}^{-1}$ (CH2), $2870 \mathbf{c m}^{-1}(\mathrm{C}-\mathrm{H}), 1666 \mathbf{~ c m}^{-1}$ $(\mathrm{C}=\mathrm{O}), 1649 \mathbf{c m}^{-1}(\mathrm{O}=\mathrm{C}-\mathrm{NH} 2), 1614 \mathbf{c m}^{-1}$ Conjugated $\mathrm{C}=\mathrm{C}$ (aromatic), $886 \mathbf{~ c m}^{-1}(\mathrm{C}=\mathrm{CH} 2)$ are shown in (Fig. 7). In current study Fig. 7 (a, b and c) exhibits the FTIR spectra of pure atenolol, formulations F35 (sintered) and F36 (compressed matrix pellets), revealing no interaction between drug and excipients even after thermal treatment and compression force.

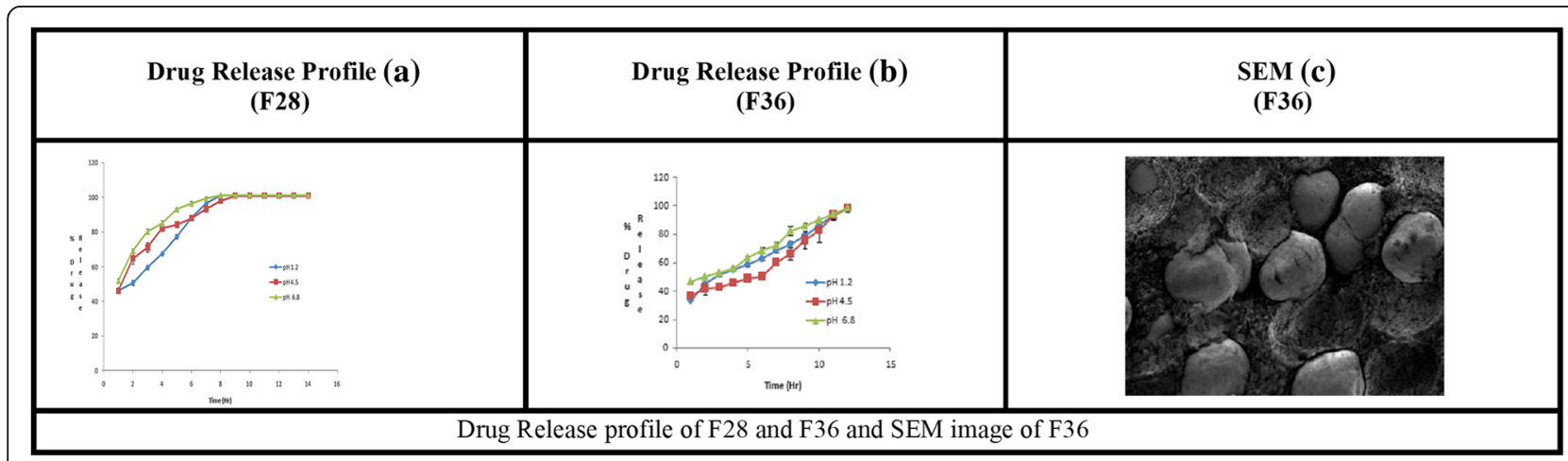

Fig. 6 Drug Release profile of F28 and F36 and SEM image of F36 
Table 4 Physical properties of compacted matrix pellet formulation (F36)

\begin{tabular}{llllll}
\hline & $\begin{array}{l}\text { Weight variation }(\mathrm{mg}) \\
(n=20)\end{array}$ & $\begin{array}{l}\text { Disintegration Time }(\mathrm{min}) \\
(n=6)\end{array}$ & $\begin{array}{l}\text { Crushing Strength }(\mathrm{Kg}) \\
(\mathrm{n}=20)\end{array}$ & $\begin{array}{l}\text { Assay (\%) } \\
(n=10)\end{array}$ & $\begin{array}{l}\text { Friability (\%) } \\
\text { F36 }\end{array} 130 \pm 1.03$ \\
\hline
\end{tabular}

\section{Drug release kinetics}

All trial formulations (F00-F36) were subjected to different release kinetic models (zero order, first order, Higuchi, Korsmeyer-Peppas, Hixson-Crowell, and BakerLonsdale) using DD solver (MS excel based Add-in program). Results revealed (Table 5) that Korsmeyer-Peppas was the best-fitted model to F35 at dissolution media $\mathrm{pH} 1.2,4.5$ and 6.8, i.e. $\mathrm{r}^{2}=0.9975, \mathrm{r}^{2}=0.975$ and $\mathrm{r}^{2}=$ 0.995 respectively, showing an-Fickian diffusion from polymeric lipid and cellulose based matrix system. F36 followed zero order kinetic release at $\mathrm{pH} 1.2\left(\mathrm{r}^{2}=0.986\right)$ and 6.8 ( $\mathrm{r} 2=0.989)$, showing concentration independent release of Atenolol. Zero-order rate constant $\left(\mathrm{k}_{0}\right)$ increased upon the application of compression force in all dissolution media. But at $\mathrm{pH} 4.5$ the best-fitted model was Korsmeyer-Peppas $\left(r^{2}=0.971\right)$ showing, non-Fickian drug release.

\section{Stability}

The optimized Atenolol pellets (F35-F36) were stored according to $\mathrm{ICH}$ guidelines at $40^{\circ} \mathrm{C} / 75 \% \mathrm{RH}$ for 12 months. Percent assay and dissolution profiles at 3, 6, 9 and 12 months (Table 6) were determined. No significant difference was observed in surface morphology and release pattern of the drug. Statistical software Minitab (V: 17.0.1) was used to calculate the shelf life and found to be 43 months (F35) and 61 months (F36).

\section{Discussion}

The extended release pellets of highly water soluble drug (BCS class III) Atenolol were designed by using response surface methodology (RSM) through software Design-Expert 10.0.8 (State-Ease, Inc., USA.) and prepared by extrusion and spheronization method. The effect of cellulose based polymers (HPMC K4, 15 \& $100 \mathrm{M}$ and EC 7, 10 \& 100cps) and lipids (GMS \&CW) alone and in combination, sintering and compaction, was observed on Atenolol release. Singh et al. in 2012 also used central composite design (CCD) and optimized SR pellets of Furosemide, to increase the bioavailability of the drug. For that purpose 1:3 ratio of drug and polymer (Coat L-100) along with the microcrystalline cellulose (MCC) were used and shaped by extrusion and spheronization. CCD used to optimize the drug while the process parameters were characterized by RSM. Results of dissolution carried out in USP apparatus I, indicated the significant difference between the drug release from SR pellet, commercial products and active [51].

Similarly, Thommes and Kleinebudde also worked on the physical characterization of pellets, containing kappa-carrageenan as an alternate to microcrystalline cellulose as pelletization aid, and reported the quality of pellets as independent of the type of filler and drug incorporated [52].

The different grades of HPMC (K4M, K15 M \& K100 M) and concentration (5-205) with Atenolol produced dumbbell shaped pellets with less percentage yield and complete release of drug in the first hour. Nasiri et al. reported that all grades of HPMC failed to control the release of itopride hydrochloride (BCS class I drug) up to $12 \mathrm{~h}$ [35], similarly, Palmer et al. also observed the $\mathrm{pH}$-independent release of ibuprofen from Poly Ethylene Oxide-HPMC matrix pellets [53].

Highest grade (EC 100FP) and concentration (20\%), of ethyl cellulose (EC), failed to spheronize and retard the release of Atenolol from pellets with poor percentage yield. Dabbagh et al. reported that the rate of drug release

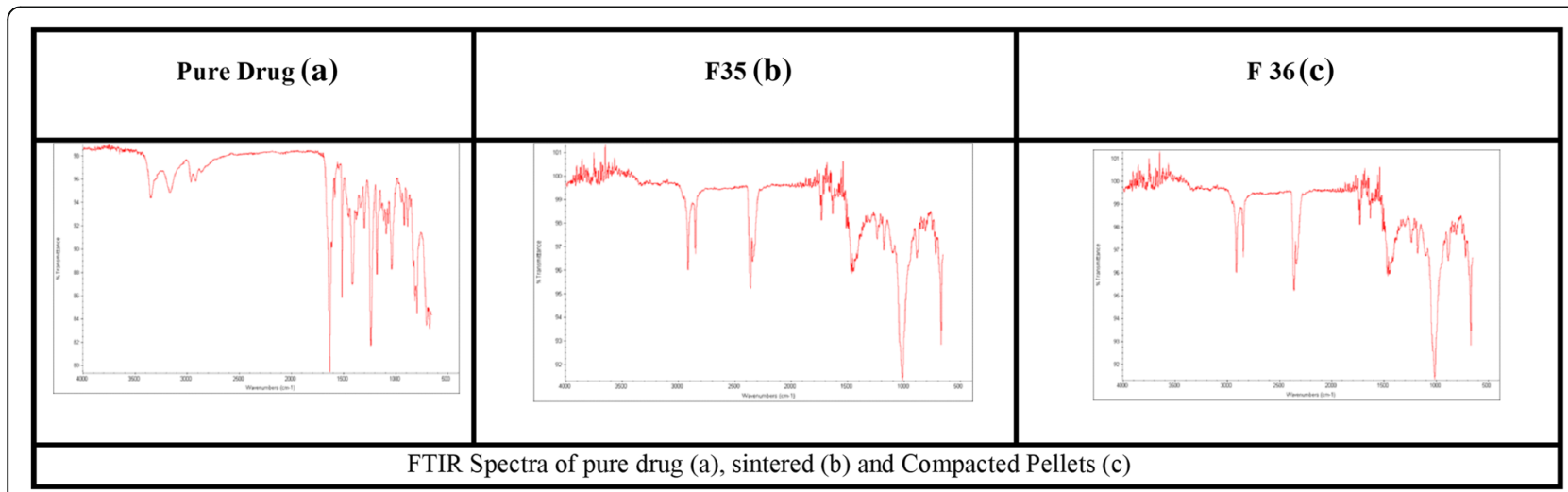

Fig. 7 FTIR Spectra of pure drug (a), sintered (b) and (c) Compacted Pellets 
Table 5 Drug release kinetics of optimized formulations

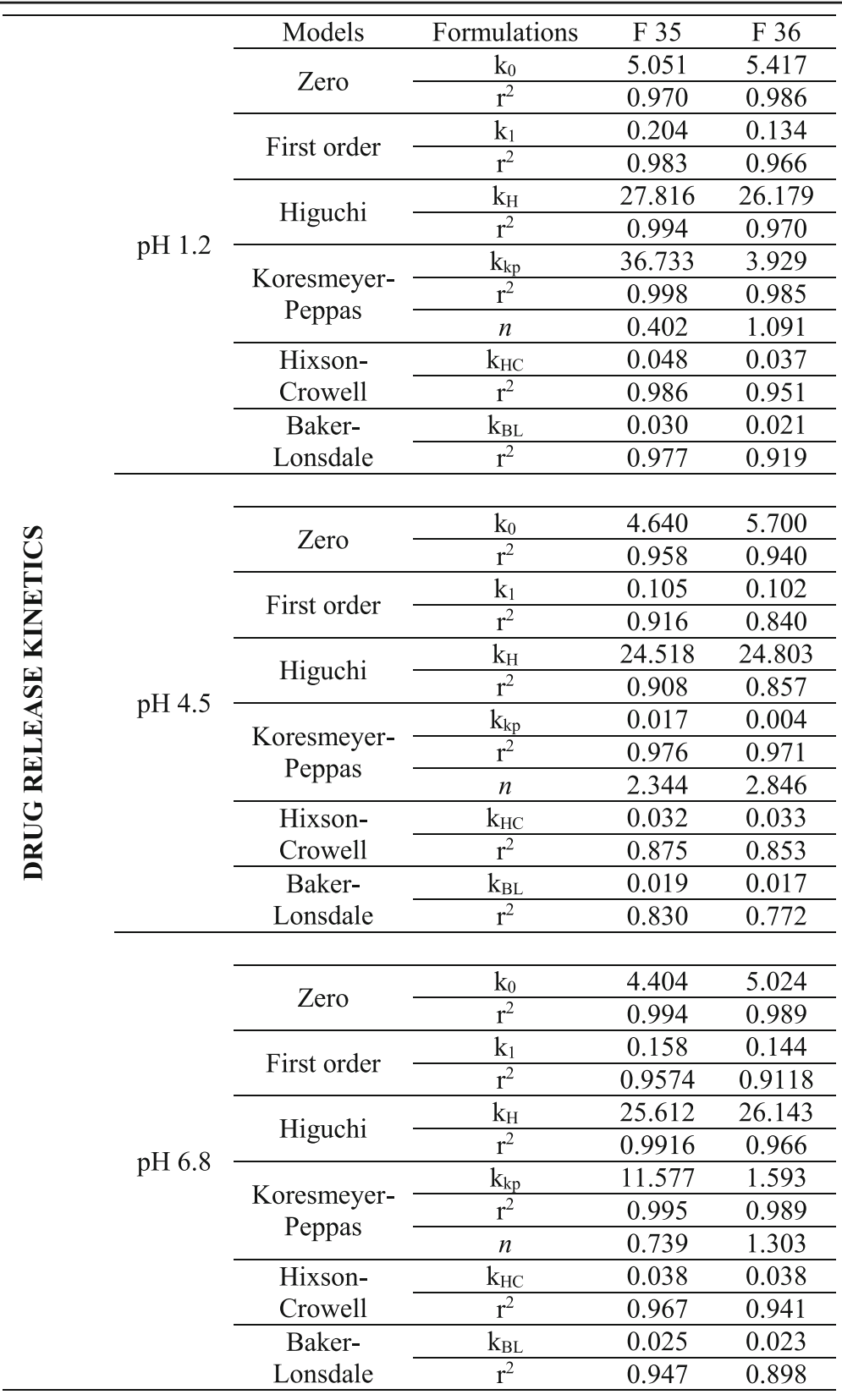

decreased with the use of higher viscosity grades of EC, and reduction in particle size of polymer prolonged the release of Propranolol hydrochloride from ethyl cellulose-based matrix pellets, due to quick surface gel formation [54].

Due to high HLB value (3.8) [55], hydration and pore forming capability [56], GMS remained unable to control the release of Atenolol but showed best spherical pellets. Cheboyina and Wyandt stated that GMS pellets reduced drug release depending on physicochemical properties of the drug (such as solubility) [57].

Carnauba wax (CE) despite low wettability and hydrophobicity also failed to control the Atenolol release when used alone. The sphericity of pellets also became poor and irregular with CW [58]. Faaiza et al. reported that the $\mathrm{CW}$ is the best release retarding agent for poorly soluble drug- Meclizine $\mathrm{HCl}$ due to the absence of pores but destruct the morphology of pellets [59]. While, previously reported studies showed that the

Table 6 Shelf life of optimized formulations

\begin{tabular}{lll}
\hline S. No & Formulations & Shelf life (months) \\
\hline 1 & F35 & 43 \\
2 & F36 & 61 \\
\hline
\end{tabular}


release of theophylline was retarded up to $3 \mathrm{~h}$ only and showed burst release was found even when CW was used in higher concentrations $[4,15]$.

Combination of ethyl cellulose (EC100FP) with waxes (GMS \& CW), in the concentrations of $20,20 \%$ \& $10 \%$ respectively retarded drug release up to $12 \mathrm{~h}$. This combination, however, remained unable to control the initial drug release at first hour, which was then controlled by thermal treatment. Upon heating $\mathrm{CW}$ releases from pellets and forms a hydrophobic waxy layer on to the pellets surface, this behavior participates in controlling drug release [15].

Compaction of Atenolol pellets containing EC 10FP (20\%), GMS (20\% and CW (10\%), retarded drug release up to $12 \mathrm{~h}$ and controlled also controlled the initial burst release by reducing the surface area. Santos et al. also evaluated the compacted pellets of diclofenac sodium and ibuprofen composed of xanthan gum and characterized the drug release from tablets made from pellets [60].

The release of Atenolol showed different patterns with different formulation variables. All grades of cellulose polymers (HPMC \& EC) (5-20\%) released the drug completely within $4-5 \mathrm{~h}$ and unable to control the drug up to $12 \mathrm{~h}$ in the formulations. The same pattern was shown by GMS (10-50\%) in the formulations. CW (5$20 \%$ ) retarded the release up to $4 \mathrm{~h}$ only with the low initial release in comparison to GMS $[4,61]$.

The release of Atenolol was best suggested by Korsmeyer-Peppas model showing non-Fickian diffusion. The drug was dissolved through multiple mechanisms, leading to the softening of the matrix and followed by pore and channel formation. The same results were also reported by different researchers for different highly soluble drugs $[55,62,63]$.

The SEM elaborated that sphericity and smoothness of EC100FP and lipids (GMS \& CW) were superior. The Highest grade of EC and lipids (GMS \& CW) form complex structure. Surface roughness and rigidity of pellets were controlled by the addition of GMS. Kleinebudde in 1997 introduced crystallite gel model of MCC in wet granulation, extrusion, and spheronization and reported that in the presence of water, MCC form a framework of cross-linking with hydrogen bonds, that results in the delicate network [64].

The IR frequency band of pure Atenolol has been reported by Eri et al. in 2014 [65]. The compatibility study showed no significant difference in the spectrum of pure Atenolol and that in optimized formulations. Only some additional peaks were observed before the spectra of Atenolol, might be associated with the different composition of CW. A researcher has also reported extra peaks of aluminum, copper, and zinc, in $\mathrm{CW}$ spectrum, due to its vegetable origin [59].
The stability of the optimized formulations was studied on accelerated conditions using $\mathrm{ICH}$ guidelines $\left(40^{\circ} \mathrm{C} / 75 \% \mathrm{RH}\right)$ and found to be stable by means of the content assay and release profile. Kibria et al. reported anomalous drug release profile of ambroxol hydrochloride (highly soluble drug) when subjected to stability condition of $40^{\circ} \mathrm{C} / 75 \% \mathrm{RH}[66]$.

\section{Conclusion}

The combination of CW (10\%) GMS (20\%) and EC 10FP (20\%) in pellet formulation, could control the drug release of highly soluble drug after compaction for $12 \mathrm{~h}$. On the other hand, the combination of EC100FP (20\%), GMS (20\%) and CW (10\%) could control the burst release of drug at 1st hour after the thermal treatment of pellets at $90^{\circ} \mathrm{C}$ for $120 \mathrm{~s}$. Atenolol is given both once daily and twice daily IR dosage forms in a different disease condition. Better designed once-daily extended release encapsulated or compacted Atenolol pellets is a better choice where patients will get controlled drug levels in the blood with a reduced side effect.

\section{Abbreviations \\ ANOVA: Analysis of variance; AR: Aspect Ratio; BCS: Biopharmaceutics Classification System; CCD: Central Composite Design; CW: Carnauba wax; EC: Ethyl cellulose; ER: Extended release; FTIR: Fourier Transform Infrared spectroscopy; GMS: Glyceryl monostearate; HPMC: Hydroxypropyl methylcellulose; ICH: International Conference on Harmonisation; MCC: Microcrystalline cellulose; PRESS: Predicted Residual Error Sum of Squares; RSM: Response surface methodology; SD: Standard Deviation; SEM: Scanning electron microscope}

\section{Acknowledgments}

Authors would like to acknowledge Morgan chemicals and Paradise International for providing waxes and cellulose based polymers.

\section{Availability of data and material}

The datasets used and/or analyzed during the current study are available from the corresponding author on reasonable request.

\section{Funding}

There is no research funding for this project. The project completed after utilizing the available resources in the Department.

\section{Authors' contributions}

MM has done the major research work including the bench work, RIY was the research supervisor, MHS provides guidance in the use of sintering, compaction and kinetic modeling, IN has given technical guidance in bench work especially Extrusion and Pelletization, TN analyzed the sample, HFA helps in chromatographic analysis and assay procedures, WI helps in formulation optimization. All authors read and approved the final manuscript.

\section{Ethics approval and consent to participate}

Not applicable.

\section{Competing interests}

The authors declare that they have no competing interests.

\section{Publisher's Note}

Springer Nature remains neutral with regard to jurisdictional claims in published maps and institutional affiliations. 


\section{Author details}

'Department of Pharmaceutics, Faculty of Pharmacy and Pharmaceutical Sciences, University of Karachi, Karachi 75270, Pakistan. ${ }^{2}$ Faculty of Pharmacy, Jinnah University for Women, Karachi 74600, Pakistan.

\section{Received: 30 April 2018 Accepted: 16 May 2018}

Published online: 09 June 2018

\section{References}

1. Zeng W. Oral controlled release formulation for highly water-soluble drugs: drug-sodium alginate-xanthan gum-zinc acetate matrix. Drug Dev Ind Pharm. 2004:30:491-5.

2. Remington: The Science and Practice of Pharmacy 20th edn: Philadelphia College of Pharmacy and Science; 2000.

3. Dixit N, Maurya SD, Sagar BP. Sustained release drug delivery system. Indian J Res Pharm Biotechnol. 2013;1:305.

4. Quadir MA, Rahman MS, Karim MZ, Akter S, Awkat M, Reza M. Evaluation of hydrophobic materials as matrices for controlled-release drug delivery. Pak 」 Pharm Sci. 2003;16:17-28.

5. Zhou F, Vervaet C, Remon JP. Matrix pellets based on the combination of waxes, starches and maltodextrins. Int J Pharm. 1996;133:155-60.

6. Jiménez A, Fabra M, Talens $P$, Chiralt A. Effect of lipid self-association on the microstructure and physical properties of hydroxypropyl-methylcellulose edible films containing fatty acids. Carbohydr Polym. 2010;82:585-93.

7. Nish S, Mathew G, Lincy J. Matrix tablets: an effective way for oral controlled release drug delivery. Iranian J Pharm Sci. 2012:8:165-70.

8. Pozzi F, Furlani P, Gazzaniga A, Davis S, Wilding I. The time clock system: a new oral dosage form for fast and complete release of drug after a predetermined lag time. J Control Release. 1994;31:99-108.

9. Anepu S, Duppala L, Pratyusha PV. Development of Hydrophobic Carriers based tablets for Sustained Release of Verapamil. J Rev Pure Appl Pharmacol Sci. 2015;5:125-134.

10. Dassanayake LSK, Kodali DR, Ueno S, Sato K. Physical properties of rice bran wax in bulk and organogels. J Am Oil Chem Soc. 2009:86:1163.

11. Enayatifard R, Saeedi M, Akbari J, Tabatabaee YH. Effect of hydroxypropy methylcellulose and ethyl cellulose content on release profile and kinetics of diltiazem HCl from matrices. Trop J Pharm Res. 2009:8(5):425-32.

12. Feng $H$, Zhang $L$, Zhu C. Genipin crosslinked ethyl cellulose-chitosan complex microspheres for anti-tuberculosis delivery. Colloids Surf B: Biointerfaces. 2013;103:530-7.

13. Levis S, Deasy P. Characterisation of halloysite for use as a microtubular drug delivery system. Int J Pharm. 2002;243:125-34.

14. Sunder M, Babu NR, Victor SP, Kumar KR, Kumar TS. Biphasic calcium phosphates for antibiotic release. Trends Biomater Artif Organs. 2005;18: 213-8.

15. Singh R, Poddar S, Chivate A. Sintering of wax for controlling release from pellets. AAPS PharmSciTech. 2007;8:E175-83.

16. Bashaiwoldu AB, Podczeck F, Newton J. A study on the effect of drying techniques on the mechanical properties of pellets and compacted pellets. Eur J Pharm Sci. 2004:21:119-29.

17. Cupp M. Atenolol for Hypertension. Pharmacist's Letter. 2013;29:290104.

18. Svendsen TL, Trap-Jensen J, Carlsen JE, McNair A. Immediate central hemodynamic effects of five different beta-adrenoceptor-blocking agents, acebutolol, atenolol, pindolol, practolol, and propranolol, in patients with ischemic heart disease. Am Heart J. 1985;109:1145-50.

19. Silke B, Verma SP, Frais MA, Reynolds G, Taylor SH. Differential actions of atenolol and celiprolol on cardiac performance in Ischemic Heart Disease. J Cardiovasc Pharmacol. 1986;8 Suppl 4:S138-144.

20. Yang Y, Faustino PJ, Volpe DA, Ellison CD, Lyon RC, Yu LX. Biopharmaceutics classification of selected $\beta$-blockers: solubility and permeability class membership. Mol Pharm. 2007;4:608-14.

21. López-Sendó J, Swedberg K, McMurray J, Tamargo J, Maggioni AP, Dargie H, Tendera M, Waagstein F, Kjekshus J, Lechat P. Expert consensus document on $\beta$-adrenergic receptor blockers. Eur Heart J. 2004;25:1341-62.

22. Melander A, Stenberg $P$, Liedholm H, Schersten B, Wăhlin-Boll E. Foodinduced reduction in bioavailability of atenolol. Eur J Clin Pharmacol. 1979; 16:327-30.

23. Lotfipour F, Nokhodchi A, Saeedi M, Norouzi-Sani S, Sharbafi J, Siahi-Shadbad $M$. The effect of hydrophilic and lipophilic polymers and fillers on the release rate of atenolol from HPMC matrices. II Farmaco. 2004;59:819-25.
24. Manivannan R, Chakole V. Formulation and development of extended release floating tablet of atenolol. Int J Recent Adv Pharm Res. 2011;3:25-30

25. Hamedelniel E, Bajdik J, Sovány T, Kasa Jr P, Pintye-Hodi K. Effects of the wetting liquid and ethylcellulose on the properties of atenolol-containing pellets. J Drug Deliv Sci Technol. 2011;21:195-200.

26. Amidon $G L$, Lennernäs $H$, Shah VP, Crison JR. A theoretical basis for a biopharmaceutic drug classification: the correlation of in vitro drug product dissolution and in vivo bioavailability. Pharm Res. 1995;12:413-20.

27. Mirfazaelian A, Tabatabaeifar M, Rezaee S, Mahmoudian M. Bioequivalence study of atenolol: pharmacokinetic and pharmacodynamic evaluation. DARU J Pharm Sci. 2003;11:95-8.

28. Robinson J, Eriksen S. Theoretical formulation of sustained-release dosage forms. J Pharm Sci. 1966;55:1254-63.

29. Berggren J, Alderborn G. Drying behavior of two sets of microcrystalline cellulose pellets. Int J Pharm. 2001:219:113-26.

30. Choudhury PK, Kar M. Controlled release metformin hydrochloride microspheres of ethyl cellulose prepared by different methods and study on the polymer affected parameters. J Microencapsul. 2009; 26:46-53.

31. El-Shanawany S. Sustained release of nitrofurantoin from inert wax matrixes. J Control Release. 1993:26:11-9.

32. Kondaiah A, Prakash K. Design of controlled release non-erodible polymeric matrix tablets of theophylline using sintering technique. Indian J Pharm Sci. 2002;64:239-43.

33. Luk C, Jane H. Sintering in pharmaceutics. Encyclopedia Pharm Technol. 1996;14:87-101.

34. Santos H, Veiga F, Pina ME, Sousa JJ. Compaction, compression and drug release properties of diclofenac sodium and ibuprofen pellets comprising xanthan gum as a sustained release agent. Int J Pharm. 2005;295:15-27.

35. Nasiri Ml, Yousuf Rl, Shoaib MH, Fayyaz M, Qazi F, Ahmed K. Investigation on release of highly water soluble drug from matrixcoated pellets prepared by extrusion-spheronization technique. J Coat Technol Res. 2016;13:333-44.

36. Schilling SU, Shah NH, Malick AW, McGinity JW. Properties of melt extruded enteric matrix pellets. Eur J Pharm Biopharm. 2010;74:352-61.

37. Dukić-Ott A, Thommes M, Remon JP, Kleinebudde P, Vervaet C. Production of pellets via extrusion-spheronisation without the incorporation of microcrystalline cellulose: a critical review. Eur J Pharm Biopharm. 2009:71:38-46.

38. Convention USP. USP35 NF30, 2012: U. S. Pharmacopoeia National Formulary. United States Pharmacopeial; 2011.

39. Young CR, Dietzsch C, McGinity JW. Compression of controlled-release pellets produced by a hot-melt extrusion and spheronization process. Pharm Dev Technol. 2005:10:133-9.

40. Dashevsky A, Kolter K, Bodmeier R. Compression of pellets coated with various aqueous polymer dispersions. Int J Pharm. 2004;279:19-26.

41. Zhang Y, Huo M, Zhou J, Zou A, Li W, Yao C, Xie S. DDSolver: an add-in program for modeling and comparison of drug dissolution profiles. AAPS J. 2010;12:263-71.

42. Narsimhan B, Mallapragada S, Peppas N. Release kinetics, Data Interpretation. In Encyclopedia of Controlled Drug Delivery. Edited by E M: Wiley; 1999.

43. Higuchi T. Mechanism of sustained-action medication. Theoretical analysis of rate of release of solid drugs dispersed in solid matrices. J Pharm Sci. 1963:52:1145-9.

44. Baker RW, Lonsdale H: Controlled release: mechanisms and rates. In Controlled release of biologically active agents Springer; 1974: 15-71.

45. Hixson A, Crowell J. Dependence of reaction velocity upon surface and agitation. Ind Eng Chem. 1931;23:1160-8.

46. Korsmeyer RW, Peppas NA. Effect of the morphology of hydrophilic polymeric matrices on the diffusion and release of water soluble drugs. J Membr Sci. 1981;9:211-27.

47. Costa P, Lobo JMS. Modeling and comparison of dissolution profiles. Eur J Pharm Sci. 2001:13:123-33.

48. Paker-Leggs S, Neau SH. Propranolol forms affect properties of Carbopolcontaining extruded-spheronized beads. Int J Pharm. 2008:361:169-76.

49. Podczeck F, Newton JM. A shape factor to characterize the quality of spheroids. J Pharm Pharmacol. 1994:46:82-5.

50. Guideline ICH. Stability testing of new drug substances and products. Q1A (R2), current step. 2003:4:1-24.

51. Singh G, Pai RS, Devi VK. Response surface methodology and process optimization of sustained release pellets using Taguchi orthogonal array design and central composite design. J Adv Pharm Technol Res. 2012;3:30. 
52. Thommes M, Kleinebudde P. Use of $\mathrm{K}$-carrageenan as alternative pelletisation aid to microcrystalline cellulose in extrusion/spheronisation. I. Influence of type and fraction of filler. Eur J Pharm Biopharm. 2006;63:59-67.

53. Palmer D, Levina M, Nokhodchi A, Douroumis D, Farrell T, Rajabi-Siahboomi A. The influence of sodium carboxymethylcellulose on drug release from polyethylene oxide extended release matrices. AAPS PharmSciTech. 2011;12:862.

54. Dabbagh MA, Ford JL, Rubinstein MH, Hogan JE. Effects of polymer particle size, compaction pressure and hydrophilic polymers on drug release from matrices containing ethylcellulose. Int J Pharm. 1996;140:85-95.

55. Abd-Elbary A, Tadros Ml, Alaa-Eldin AA. Sucrose stearate-enriched lipid matrix tablets of etodolac: modulation of drug release, diffusional modeling and structure elucidation studies. AAPS PharmSciTech. 2013;14:656-68.

56. Roblegg E, Jäger E, Hodzic A, Koscher G, Mohr S, Zimmer A, Khinast J. Development of sustained-release lipophilic calcium stearate pellets via hot melt extrusion. Eur J Pharm Biopharm. 2011:79:635-45.

57. Cheboyina S, Wyandt CM. Wax-based sustained release matrix pellets prepared by a novel freeze pelletization technique: II. In vitro drug release studies and release mechanisms. Int J Pharm. 2008:359:167-73.

58. Reza MS, Quadir MA, Haider SS. Comparative evaluation of plastic, hydrophobic and hydrophilic polymers as matrices for controlled-release drug delivery. J Pharm Pharm Sci. 2003;6:282-91.

59. Qazi F, Shoaib MH, Yousuf Rl, Nasiri Ml, Ahmed K, Ahmad M. Lipids bearing extruded-spheronized pellets for extended release of poorly soluble antiemetic agent-meclizine HCl. Lipids Health Dis. 2017;16:75.

60. Santos H, Veiga F, Pina ME, Sousa JJ. Compaction, compression and drug release characteristics of xanthan gum pellets of different compositions. Eur J Pharm Sci. 2004;21:271-81.

61. Zeeshan F, Peh K, Tan Y. Exploring the potential of a highly compressible microcrystalline cellulose as novel tabletting excipient in the compaction of extended-release coated pellets containing an extremely water-soluble model drug. AAPS PharmSciTech. 2009;10:850.

62. Wadher KJ, Kakde RB, Umekar MJ. Formulations of sustained release metformin hydrochloride tablet using combination of lipophilic waxes by melt granulation technique. Afr J Pharm Pharmacol. 2010;4:555-61.

63. Yan X, He H, Meng J, Zhang C, Hong M, Tang X. Preparation of lipid aspirin sustained-release pellets by solvent-free extrusion/spheronization and an investigation of their stability. Drug Dev Ind Pharm. 2012:38:1221-9.

64. Kleinebudde P. The crystallite-gel-model for microcrystalline cellulose in wet-granulation, extrusion and spheronization. Pharm Res. 1997:14:804-9.

65. Eri GK, Naik MC, Padma Y, Ramana MV, Madhu M, Gopinath C: Novel FT-IR spectroscopic method for the quantitation of atenolol in bulk and tablet formulations. JGTPS; 2014.

66. Kibria G, Islam KA, Jalil R-U. Stability study of ambroxol hydrochloride sustained release pellets coated with acrylic polymer. Pak J Pharm Sci. 2009;22

\section{Ready to submit your research? Choose BMC and benefit from:}

- fast, convenient online submission

- thorough peer review by experienced researchers in your field

- rapid publication on acceptance

- support for research data, including large and complex data types

- gold Open Access which fosters wider collaboration and increased citations - maximum visibility for your research: over $100 \mathrm{M}$ website views per year

At BMC, research is always in progress.

Learn more biomedcentral.com/submissions 